\title{
Evaluating point-of-care testing for glycosylated haemoglobin in public sector primary care facilities in the Western Cape, South Africa
}

\author{
R Mash, ${ }^{1}$ MB ChB, FCFP, FRCGP, PhD; A Ugoagwu, ${ }^{1}$ MB ChB, MMed; C Vos, ${ }^{1}$ MB ChB, MMed; M Rensburg, ${ }^{2}$ MB ChB, MMed; \\ R Erasmus, ${ }^{2}$ MBBS, FMCPath (Nig), DABCC, DHSM, FCPath (SA)
}

${ }^{1}$ Division of Family Medicine and Primary Care, Faculty of Medicine and Health Sciences, Stellenbosch University, Cape Town, South Africa ${ }^{2}$ Division of Chemical Pathology, Faculty of Medicine and Health Sciences, Stellenbosch University, Cape Town, South Africa

Corresponding author: R Mash (rm@sun.ac.za)

\begin{abstract}
Background. Diabetes mellitus contributes significantly to the burden of disease in South Africa (SA). Monitoring of glycaemic control with glycosylated haemoglobin (HbAlc) is recommended, even though current laboratory-based testing does not support immediate clinical decision-making.

Objectives. To evaluate the costs and consequences for quality of care by introducing point-of-care (POC) testing for HbAlc for patients with type 2 diabetes at community health centres in Cape Town, SA.

Methods. A quasi-experimental study was conducted at two control and two intervention sites in the same sub-district. The DCA Vantage Analyzer (Siemens, Germany) for POC testing was introduced at the intervention sites for 12 months. Patients were randomly selected from the diabetes register at the intervention $(n=300)$ and control $(n=300)$ sites, respectively, and data were collected from patient records at baseline and 12 months. Focus group interviews were performed at the intervention sites. Technical quality and cost implications were evaluated.

Results. POC testing was feasible, easy to integrate into the organisation of care, resulted in more immediate feedback to patients $(p<0.001)$ and patients appeared more satisfied. POC testing did not improve test coverage, treatment intensification, counselling or glycaemic control. There was an incremental cost of ZAR2 110 per 100 tests. Compliance with quality control was poor, although control tests showed good reliability.

Conclusion. This study does not support the introduction of POC testing for HbAlc in public sector primary care practice in the current context. POC testing should be evaluated further in combination with interventions to overcome clinical inertia and strengthen primary healthcare.
\end{abstract}

S Afr Med J 2016;106(12):1236-1240. DOI:10.7196/SAMJ.2016.v106i12.10728

Diabetes mellitus is a complex, chronic disease requiring routine monitoring of glycaemic control to minimise, avoid or delay associated complications. Diabetes is an important contributor to the burden of disease in South Africa (SA), with an estimated prevalence of $6.5 \%$ for adults between 20 and 79 years of age. ${ }^{[1]}$

In the SA public sector, random blood glucose is commonly used to make clinical decisions with regard to glycaemic control, as glycosylated haemoglobin (HbAlc) tests have either not been done, or the results are not yet available or are out of date. The most suitable value of random blood glucose to predict control ( $\mathrm{HbA} 1 \mathrm{c}<7 \%$ ) is $9.8 \mathrm{mmol} / \mathrm{L}$, with a sensitivity of $77 \%$ and a specificity of $75 \%,{ }^{[2]}$ which implies that even in the best of circumstances the assessment of control will be incorrect in up to a quarter of patients.

SA guidelines recommend that HbAlc be checked every 6 months in well-controlled patients and every 3 months in uncontrolled ones or whenever treatment changes. ${ }^{[3]}$ Small but sustained reductions in $\mathrm{HbAlc}$ can lead to a significant decrease in the risk of complications. ${ }^{[4]}$

The American Diabetes Association recommends the use of point-of-care (POC) testing for HbAlc to allow for timely decisions with regard to therapeutic changes. ${ }^{[5]}$ POC testing for HbAlc has evolved with the availability of relatively cheap, reliable and accurate instruments. ${ }^{[6]}$ Research has shown that availability of test results during the same visit is associated with improvement in glycaemic control, even in poor urbanised communities. ${ }^{[7,8]}$ POC testing can improve collaboration between the patient and provider for management of the disease ${ }^{[0]}$ and lead to immediate counselling and treatment adjustment. ${ }^{[10]}$ It can save the patient time by reducing the number of clinic visits and save the practitioner the administration time of obtaining laboratory results telephonically, reviewing patient records or mailing the results to the patient ${ }^{[10]}$ POC testing has also been found to be acceptable and feasible to physicians and other staff members. ${ }^{[10]}$ It has been associated with improved patient experience and satisfaction. ${ }^{[9]}$ Despite these advantages, the cost of POC testing may be up to three times that of the normal laboratory service. ${ }^{[7]}$

Most of the research has been performed in high-resource settings. There is little evidence of whether such testing can achieve similar benefits for patients in low-resource settings or whether investing in POC testing would be a cost-effective strategy. In our setting, the Western Cape Department of Health was interested in a feasibility study to assess the technical quality, costs and consequences of POC testing for $\mathrm{HbAlc}$ in primary care.

This study, therefore, aimed to evaluate the costs and consequences of introducing POC testing for $\mathrm{HbAlc}$ in patients with type 2 diabetes mellitus at community health centres in the Western Cape, with the ultimate objective of improving their glycaemic control and quality of care. 


\section{Methods \\ Study design}

This was a quasi-experimental study that compared POC testing in two purposively selected community health centres with two similar health centres that offered usual care in the same sub-district.

\section{Setting}

The study was performed in the Helderberg sub-district of the Cape Town metropole. In the public sector, patients attend community health centres for management of their diabetes on specific 'club' days. On arrival they obtain their folder and have routine tests performed in the preparation room. They are then seen by either a clinical nurse practitioner or a doctor, if poorly controlled.

A laboratory $\mathrm{HbA1c}$ is meant to be checked once a year. Audits suggest that $70 \%$ of patients currently receive the test. ${ }^{[11]}$ Laboratory results are returned to the health centre for filing in the patients' records. The results are usually considered when the patients are next reviewed after 3-6 months.

\section{Study population}

The study population consisted of adult patients ( $>18$ years of age) with type 2 diabetes mellitus, who had been attending the community health centres for at least a year.

\section{Sample size calculation}

A sample size calculation, based on having $90 \%$ power to detect a $1 \%$ difference in $\mathrm{HbAlc}$ (standard deviation (SD) 2.23) with a $p$-value of $<0.05$ considered significant, suggested that 106 patients were required in each group $(n=212)$. To compensate for those without an $\mathrm{HbA1c}$ test result at baseline and for loss to follow up, a sample consisting of 300 patients in each group was selected.

\section{Selection of health centres and patients}

The community health centres were chosen from the same subdistrict and therefore served similar communities. Selection of the intervention sites was based on the presence of a family medicine registrar at each site to assist with implementation of the POC testing, and the control sites were selected to be as similar as possible in terms of the service provided. The two registrars also performed the duties of research assistants.

At each health centre, 150 patient records were randomly selected from the club register using computer-generated random numbers. The staff at the health facilities were not aware of the identity of patients who were selected for the study.

\section{Intervention}

The DCA Vantage Analyzer (Siemens, Germany) for POC testing was used in this study (Fig. 1). It has a time to HbAlc result of 6 minutes and is able to detect results within the range of $2.5-14 \%$.

At the intervention sites, 2 - 3 members of the chronic care team were trained by Siemens staff to operate the POC machine and received competency certificates. The location of the POC machine and its integration into the process of care were negotiated with the local chronic care teams.

POC testing was performed according to a standardised operating procedure, with the goal of one test per patient over 12 months. Additional tests could be performed if the doctor felt it was clinically necessary. POC testing was discontinued after 12 months.

The HbAlc test result was entered into the patient record; the patient was then managed according to the usual guidelines and practice at the health facility. No attempt was made to provide

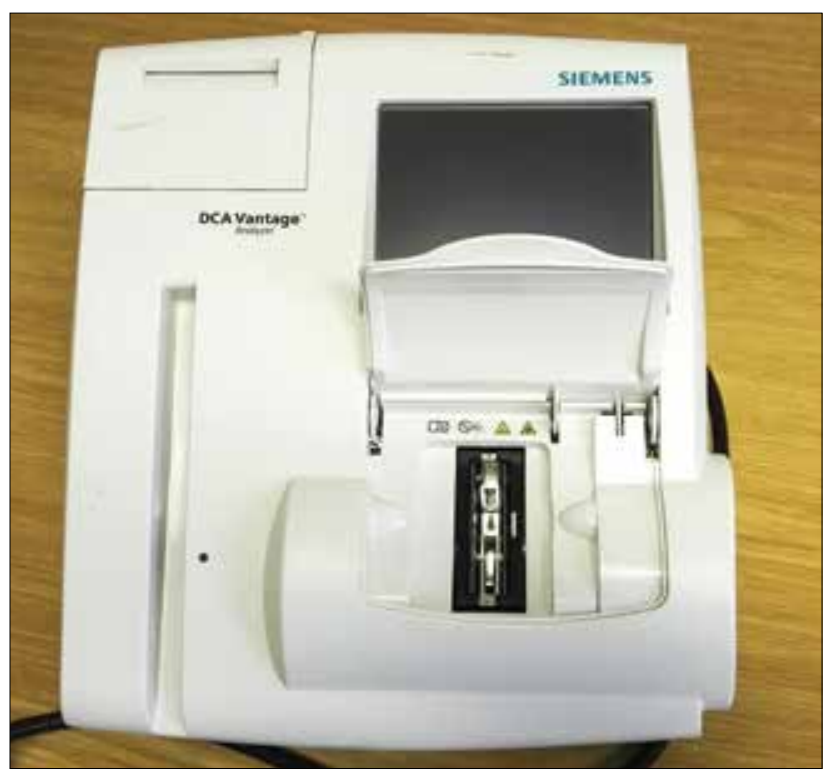

Fig. 1. The DCA Vantage Analyzer for POC testing in a primary care facility.

additional training in the management of diabetes and interpretation of the HbAlc test.

The technical quality of the POC machine was assessed using weekly internal quality control measures, which involved control reagents, and monthly external quality control, comparing the POC test result with the laboratory result with regard to the same patient during the same visit.

\section{Data collection}

Data were collected retrospectively at baseline and 12 months later from the medical records to assess $\mathrm{HbAlc}$ testing, medication use and counselling over the preceding year. Demographic and clinical data were also collected at baseline. Data for quality control were obtained from the register kept with the POC machine. HbAlc results of all patients were obtained at 18 months from the laboratory database. At the end of the study, focus group interviews were conducted by an independent researcher with the chronic care teams at the intervention sites to explore their experience of using the POC machine. Data were also collected on the incremental cost of salaries (staff time) and resources used.

\section{Data analysis}

Data were entered into an Excel (Microsoft, USA) spreadsheet and checked prior to analysis by the Biostatistics Unit, Faculty of Medicine and Health Sciences, Stellenbosch University, using Statistica 13.0 (Dell, USA).

Descriptive statistics reported on frequencies and percentages or means and SDs. Both categorical and continuous data were paired at baseline and follow-up and any change in category or numerical difference was evaluated. Inferential statistics were then used to compare the differences between the intervention and control groups. Pearson's $\chi^{2}$ test was used to compare categorical variables between the two groups. Continuous numerical data were analysed using the $t$-test of proportion, if normally distributed. If not normally distributed, the two-sample Wilcoxon rank-sum (Mann-Whitney) test was used for analysis.

The cost of testing was analysed based on the time taken to perform the test and the salary of the nurse performing it, as well as the costs of all materials used. These costs were then compared with 
those of laboratory testing and costs saved by not performing the random blood glucose tests.

Qualitative data were transcribed verbatim and checked against the original audio recording. Data were then analysed using the framework method (familiarisation, thematic index, coding, charting, interpretation).

\section{Ethical considerations}

The Health Research Ethics Committee, Stellenbosch University approved the study (ref. no.: N13/02/026). Permission to conduct the study was obtained from the Western Cape Department of Health and the facility managers of the health facilities.

\section{Results}

\section{Study sample}

Data of patients with type 2 diabetes were obtained from the four community health centres $(n=600)$, from the intervention sites $(n=300)$, and from the control sites $(n=300)$. The mean age of the patients in the study sample was 56.7 (SD 13.0) years and 385 (64.2\%) were females. Table 1 presents a profile of key diabetes indicators in the study sample.

Table 2 indicates differences in healthcare workers' use of HbAlc testing in both groups. There was a statistical difference in terms of the frequency of testing, which was the primary outcome of the study; however, this was because fewer people in the control group were being tested. At follow-up, there were 139 (46.3\%) patients in the intervention group who received their result on the same day compared with $0(0.0 \%)$ patients in the control group $(p<0.001)$. The mean turnaround time for the test result decreased in both groups, but on follow-up it was significantly lower in the POC group (mean 10.1 v. 63.6 days; $p<0.001$ ). POC testing, therefore, resulted in more immediate feedback to the patients with regard to the level of their glycaemic control. Glycaemic control, however, was not significantly improved in the POC group at 18 months from baseline.

There was no significant improvement in the number of additional patients who received metformin, gliclazide, glibenclamide, protaphane or actraphane in the intervention group and no significant increase in the mean dose of these medications.

In the control group, 25 (8.3\%) additional patients were referred for counselling compared with 5 (1.7\%) fewer in the intervention group $(p=0.007)$. There was no difference in patients counselled in the consultation (control group 38 (12.7\%) additional patients v. intervention group 28 (9.3\%) additional patients; $p=0.736$ ). There was therefore no positive effect on patient education and counselling in the POC group receiving immediate feedback on glycaemic control.

\section{Technical quality}

For the internal quality assessment of the expected tests, only 25 of $104(24.0 \%)$ of the normal controls and 27 of $104(26.0 \%)$ of the abnormal controls were included. All the values (100\%) of the control tests were within the acceptable range for normal $(4.2-6.4 \%)$ and abnormal (8.9 - 13.3\%) controls. The mean HbAlc result for the normal control values was $5.3 \%$, with an $\mathrm{SD}$ of 0.42 , while the mean for the abnormal control values was $10.8 \%$, with an SD of 0.29 .

For the external quality assessment only 6 of $24(25.0 \%)$ of the expected tests were performed. The Spearman correlation coefficient between the laboratory tests and POC test results in the external quality assessment was 0.80 , indicating a strong association.

Table 1. Baseline profile of the study sample

\begin{tabular}{|c|c|c|c|}
\hline Variable & $\begin{array}{l}\text { Patients }(n=600) \text {, } \\
\text { mean }(S D)\end{array}$ & $\begin{array}{l}\text { Intervention group } \\
(n=300) \text {, mean (SD) }\end{array}$ & $\begin{array}{l}\text { Control group } \\
(n=300), \text { mean (SD) }\end{array}$ \\
\hline Age (years) & $56.7(13.0)$ & $55.0(13.1)$ & $58.5(12.6)$ \\
\hline Body mass index $\left(\mathrm{kg} / \mathrm{m}^{2}\right)$ & $32.1(6.9)$ & $32.8(6.9)$ & $31.4(6.8)$ \\
\hline HbAlc (\%) & $9.1(2.5)$ & $8.8(2.3)$ & $9.4(2.6)$ \\
\hline Random blood glucose (mmol/L) & $10.4(4.7)$ & $11.1(5.1)$ & $9.7(4.2)$ \\
\hline Systolic blood pressure (mmHg) & $144.9(24.4)$ & $147.3(25.4)$ & $142.4(23.2)$ \\
\hline Diastolic blood pressure (mmHg) & $82.7(12.6)$ & $83.3(14.0)$ & $82.1(11.1)$ \\
\hline Total cholesterol (mmol/L) & $5.1(1.2)$ & $5.0(1.1)$ & $5.1(1.4)$ \\
\hline \multirow[t]{2}{*}{ Creatinine $(\mu \mathrm{mol} / \mathrm{L})$} & $81.6(68.5)$ & $74.6(51.8)$ & $89.6(82.9)$ \\
\hline & $n(\%)$ & $n(\%)$ & $n(\%)$ \\
\hline Female & $385(64.2)$ & $192(64.0)$ & $193(64.3)$ \\
\hline Male & $215(35.8)$ & $108(36.0)$ & $107(35.7)$ \\
\hline
\end{tabular}

Table 2. Comparing HbAlc testing in intervention and control groups

\begin{tabular}{|c|c|c|c|}
\hline Variable & $\begin{array}{l}\text { Change in intervention } \\
\text { group }(n=300), n(\%)\end{array}$ & $\begin{array}{l}\text { Change in control group } \\
(n=300), n(\%)\end{array}$ & $p$-value \\
\hline Additional $\mathrm{HbAlc}$ tests done & $4(1.3)$ & $-24(8.0)$ & 0.007 \\
\hline \multirow[t]{2}{*}{ Additional patients having $>1 \mathrm{HbA} 1 \mathrm{c}$ test performed } & $4(1.3)$ & $0(0.0)$ & 0.297 \\
\hline & Mean (SD) & Mean (SD) & \\
\hline Mean difference in $\mathrm{HbAlc}$ result (\%) at 12 months & $-0.44(1.8)$ & $0.13(2.1)$ & 0.032 \\
\hline Mean difference in $\mathrm{HbAlc}$ result (\%) at 18 months & $0.00(1.5)$ & $0.50(2.0)$ & 0.107 \\
\hline
\end{tabular}




\section{Cost analysis}

The calculation assumes that intravenous blood must still be drawn annually to test for cholesterol and creatinine, a glucometer will still be needed, and transport costs remain the same for other specimens. The costs of printing the laboratory results on paper, delivering it to the health centre and filing the results were not included. The cost of electricity to run the machine was difficult to calculate and was not included, but would not add significantly to the cost. POC testing was thought not to increase the cost of medical waste disposal for the facility. The cost of some patients returning for an additional visit to obtain their result was also not included. Most patients receive their result at their next routine visit. The additional time taken to perform the POC test (4 minutes) was partially offset by the time saved by not performing the finger-prick random blood glucose test during that visit ( 2 minutes). Overall, therefore, the testing would require an additional ZAR21.10 per patient per year. These costs may be considerably less if the HbAlc cartridges are purchased in bulk. Although the cost of the POC instrument is included, it is usually incorporated into the purchase cost of the cartridges.

\section{Observations and feedback from staff}

One of the sites had to replace the POC analyser, as it was faulty during the study, and both sites experienced brief periods without a supply of cartridges. Staff reported that the POC analyser was easy to use and integrate into the clinic. They felt that patients benefited from a reduced number of visits and having their treatment modified immediately. Although the analyser took 6 minutes to process the sample, the staff performed other tasks during that time. The register of HbAlc results that was kept with the machine was useful for clinical governance. Patients appeared more satisfied because the quality of service was visibly improving, they received immediate feedback on their glycaemic control, and a venous sample did not have to be taken. Staff believed that seeing the test performed and receiving the result immediately helped to motivate lifestyle change. Staff expressed a desire for a POC analyser that would also measure cholesterol and creatinine.

\section{Discussion}

POC testing for HbAlc resulted in significantly more immediate feedback to patients about their glycaemic control. However, it did not lead to an increase in the percentage of patients having the test or tempt staff to break with local policy and perform testing more frequently. The use of POC testing did not lead to any effect on treatment intensification, patient education or counselling.

Surprisingly, the coverage of annual $\mathrm{HbAlc}$ testing in the diabetic population did not improve, despite the availability of POC testing. This may indicate that the way in which care is organised and how patients flow through the facilities have a greater impact on who is tested than the availability of POC testing.

Studies elsewhere have clearly shown that POC testing during the same visit can be associated with improved glycaemic control. ${ }^{[7,8]}$ In the SA public sector primary care context, however, this was not the case. There appeared to be a high level of clinical inertia in the face of clear and immediate evidence of poor control. A lack of clinical responsiveness could be due to poor understanding of the clinical guidelines, lack of confidence, or reluctance to follow the guidelines, particularly the initiation of insulin. Interventions that required additional time or commitment might have been avoided in the face of the high workload. Nurses, who provide the bulk of chronic care, may have lacked the capability to manage poor glycaemic control. Local studies have shown a significant lack of knowledge about lifestyle modification among nurses, ${ }^{[12]}$ and the implementation of new guidelines elsewhere in the Western Cape has also had little impact on treatment intensification. ${ }^{[13]}$ In chronic care for HIV it was necessary to clearly identify and implement a different response to treatment failure to overcome similar clinical inertia. ${ }^{[14]}$ High levels of burnout have also been reported among local healthcare providers, which may impact on their capacity to implement new treatments or counselling. ${ }^{[15]}$ Strengthening of primary care providers and systems may therefore be needed before POC testing could have an effect on quality of care.

Studies have also shown that patient satisfaction is improved using POC testing, and personal knowledge of one's HbAlc level is associated with better outcomes. ${ }^{[16]}$ The qualitative feedback from the chronic care teams suggested that patients were more satisfied with POC testing, although the immediate feedback did not appear to improve self-care or adherence to the point of impacting on glycaemic control.

POC testing was feasible and relatively easy to perform and integrate into the organisation of care. It was associated with a small incremental cost, which given the lack of effectiveness in this study, would not be worth the investment in the current context.

Adherence to the quality control measures was poor, although the tests that were performed suggested that the results were reliable. If POC testing were introduced, greater supervision of technical quality would be needed.

The design of the study was quasi-experimental. One of its limitations is the lack of random allocation to intervention or control groups, which makes the possibility of confounding factors more likely. The presence of confounding factors in the organisation of care or behaviour of healthcare workers is seen in the unexpected improvement of counselling in the control group. More organised or less organised chronic care teams might have responded differently to the provision and use of the POC tests. It is possible, therefore, that different results could have been obtained if different health centres were selected. Nevertheless, it was thought that these health centres typically reflected the current organisation and quality of care in the public sector. As the quality of medical records was sometimes inadequate, the researchers struggled to extract the necessary information from these records.

\section{Conclusion}

This study does not support the implementation of POC testing for $\mathrm{HbAlc}$ in the current public sector primary care context, as it did not lead to greater coverage, intensified treatment, more counselling or improved glycaemic control. There was a significant improvement in patients receiving immediate feedback on their $\mathrm{HbAlc}$ result. POC testing was feasible, easy to perform and integrate into the organisation of care, and was associated with a negligible incremental cost. The feedback suggests that POC testing for HbAlc is feasible in primary care settings in the Western Cape. Future studies should explore the effect of introducing POC testing with interventions to strengthen primary care and overcome clinical inertia.

Acknowledgements. This work is based on research supported by the National Research Foundation of South Africa and the Chronic Disease Initiative for Africa. We thank the chronic care teams at all the study sites and Siemens for donation of the POC analysers. We also acknowledge Drs R Machekano and T Esterhuizen from the Biostatistics Unit, Faculty of Medicine and Health Sciences, Stellenbosch University for their help with data analysis. 
1. International Diabetes Federation. Diabetes Atlas. 6th ed. Brussels: IDF, 2013. http://www.idf.org/ (accessed 14 October 2016).

2. Daramola K, Mash B. The validity of monitoring the control of diabetes with random blood glucose testing. S Afr Fam Pract 2013;55(6):79-580. http://dx.doi.org/10.1080/20786204.2013.10874420

3. Amod A, Ascott-Evans BH, Berg GI, et al The 2012 SEMDSA Guideline for the management of type 2 diabetes. JEMDSA 2012;17(2):S83-S84.

4. Stratton IM, Adler AI, Neil HA, et al. Association of glycaemia with macro-vascular and microvascular complications of type 2 diabetes (UKPDS 35). BMJ 2000;321(7258):405-412. http://dx.doi. org/10.1136/bmj.321.7258.405

5. American Diabetes Association. American Diabetes Guidelines 2007: Standards of medical care in Diabetes. Position statement. Diabetes Care 2007;30(Suppl 1):S4-S41. http://dx.doi.org/10.2337/dc07-S004 6. Leal S, Soto-Rowen M. Usefulness of point of care testing in the treatment of diabetes in an underserved population. J Diabetes Sci Technol 2009;3(4):672-676. http://dx.doi.org/10.1177/193229680900300409 7. Khunti K, Stone MA, Burden AC, et al. A randomized controlled trial of near patient testing for glycated haemoglobin in patients with type 2 diabetes. Br J Gen Pract 2006;56(528):511-517.

8. Rust G, Gailor M, Daniels E, McMillan-Persuad B, Strothers H, Mayberry R. Point of care testing to improve glycaemic control. Int J Health Care Qual Assur 2008;21(3):325-335. http://dx.doi. org/10.1108/09526860810868256

9. Cagliero E, Levina EV, Nathan DM. Immediate feedback of HBA1c level improves glycaemic control in type 1 and insulin treated type 2 diabetic patients. Diabetes Care 1999;22(11):1785-1789. http://dx.doi. type 1 and insulin treated type 2 .
org $/ 10.2337 /$ diacare.22.11.1785

10. Brown JB, Harris SB, Webster-Bogaert S, Porter S. Point-of-care testing in diabetes management: What role does it play? Diabetes Spectrum 2004;17(4):244-248. http://dx.doi.org/10.2337/diaspect.17.4.244
11. De Vries E. Integrated Chronic Disease Audit Report. Cape Town: Department of Health, 2014

12. Parker WA, Steyn NP, Levitt NS, et al. They think they know but do they? Misalignment of perception

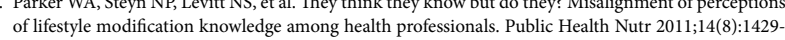
of lifestyle modification knowledge among health profs

13. Chronic Disease Initiative for Africa. Chronic Disease Initiative Annual Report. 2014. Pragmatic cluster randomised controlled trial of a guideline-based intervention to improve the primary care of non-communicable diseases in the Eden and Overberg districts of the Western Cape. http://www.cdia. uct.ac.za (accessed 1 March 2016).

14. Médecins Sans Frontières. Khayelitsha. Supporting adherence to antiretroviral treatment: A facility approach to reduce the risk of treatment failure. https://www.msf.org.za/sites/msf.org.za/files/risk_of treatment_failure_mentorship_toolkit_v3.pdf (accessed 10 November 2016).

15. Rossouw L, Seedat S, Emsley RA, Suliman S, Hagemeister D. The prevalence of burnout and depression in medical doctors working in the Cape Town Metropolitan Municipality community healthcare clinics and district hospitals of the Provincial Government of the Western Cape: A cross-sectional study. S Afr Fam Pract 2013;55(6)567-573. http://dx.doi.org/10.1080/20786204.2013.10874418

16. Laurence $\mathrm{CO}$, Gialamas A, Bubner TT, et al. Point of care testing in general practice trial management group. Patient satisfaction with point of care testing in general practice. Br J Gen Pract 2010;60:e98-e104. http://dx.doi.org/10.3399\%2Fbigp10X483508

Accepted 29 September 2016. 